\title{
OUTCOME OF CHILDREN TREATED WITH INVASIVE MECHANICAL VENTILATION IN PICU IN A TERTIARY CARE CENTRE, KERALA
}

\author{
Shanmugham $G^{1}$, Rajesh T. V', Babu Francis C. A3, Jayakrishnan M. $P^{4}$
}

${ }_{1}^{1}$ Resident, Department of Paediatrics, Government Medical College, Kozhikode, Kerala.

${ }^{2}$ Associate Professor, Department of Paediatrics, Government Medical College, Kozhikode, Kerala.

${ }_{3}^{3}$ Additional Professor, Department of Paediatrics, Government Medical College, Kozhikode, Kerala.

${ }^{4}$ Additional Professor, Department of Paediatrics, Government Medical College, Kozhikode, Kerala.

ABSTRACT

\section{BACKGROUND}

Mechanical ventilation (MV) has become one of the major indications for admission to paediatric ICUs and often a lifesaving strategy. However, use of MV can be associated with various complications including patient's mortality. Management of children with invasive ventilation necessitates facility for intensive monitoring as well as supportive care, which is challenging in a limited resource setup.

Aims and Objectives- The study aimed to assess the clinical profile and outcome of children treated with invasive mechanical ventilation.

\section{MATERIALS AND METHODS}

A prospective cohort study conducted in the PICU of the Department of Paediatrics, Government Medical College, Kozhikode during the period of January 2014 to June 2015. Clinical details of children given invasive mechanical ventilation for more than 24 hours were analysed.

\section{RESULTS}

Study group included 130 children, 54.6\% males and mean age of 27 months. Most had respiratory diseases with other comorbid conditions. Respiratory failure (62.3\%) was the most common indication for MV followed by airway protection (28.5\%) and persistent shock (9.2\%). Most common initial ventilatory mode used was SIMV. Mean (SD) duration of ventilation was 5.1 (5.24) days. Reintubation was required in 59.2\% children, mostly due to ET tube obstruction. Among 130 children, 63 children (48.5\%) developed a total of 116 complications equating to 175 complications per 1,000 days of ventilation. Failed extubation (22.3\%), VAP $(16.9 \%)$ and post extubation stridor (13.8\%) were the common complications. Total mortality was $54.6 \%$ and majority were infants. Pneumonia with sepsis (54.8\%) was the admitting diagnosis in most of those expired. Duration of MV, prolonged requirement of higher $\mathrm{FiO}_{2}$ and development of complications were associated with mortality.

\section{CONCLUSION}

Prolonged duration of ventilation was significantly associated with complications as well as mortality related to mechanical ventilation. High rate mortality occurred in infants and in those with underlying chronic diseases.

\section{KEY WORDS}

Mechanical Ventilation, Bronchopneumonia, Respiratory Failure, Ventilator Associated Pneumonia, Atelectasis, Complications, Clinical Outcome.

HOW TO CITE THIS ARTICLE: Shanmugham G, Rajesh TV, Francis BCA, et al. Outcome of children treated with invasive mechanical ventilation in PICU in a tertiary care centre, Kerala. J. Evolution Med. Dent. Sci. 2018;7(19):2342-2346, DOI: $10.14260 /$ jemds/2018/528

\section{BACKGROUND}

Mechanical Ventilation (MV) has become a crucial interventional strategy in the management of critically ill children. Ventilatory support may be needed not only in respiratory system diseases but in situations such as sepsis and septic shock, neuromuscular diseases, during postoperative state and in cases of altered mental status with loss of consciousness as well. In many cases, mechanical ventilation can be lifesaving. Thus, mechanical ventilation

'Financial or Other Competing Interest': None.

Submission 24-03-2018, Peer Review 18-04-2018,

Acceptance 24-04-2018, Published 07-05-2018.

Corresponding Author:

Dr. Rajesh T. V,

Nikunjam, 30/433, B1,

Chevayur (PO), Kozhikode-673017,

Kerala.

E-mail:drrajeshtv@gmail.com

DOI: $10.14260 /$ jemds $/ 2018 / 528$

\section{(c) $(1)(-$}

(MV) has become one of the major indications for admission to intensive care units.

However, use of mechanical ventilation can be associated with complications and adverse physiologic effects ${ }^{[1]}$ which may prolong the duration of MV itself, duration of hospitalisation and increased patient mortality.[2,3] Also, its use necessitate intensive monitoring, both invasive and noninvasive as well as additional supportive care adding to the treatment cost. Most Paediatric Intensive Care Units (PICU) are equipped with limited number of ventilators compared to the number of sick children they cater. In this circumstance selection of appropriate patient for ventilatory support is crucial, especially in a limited resource setup. Hence, knowing the clinical profile, pattern of complications and risk for mortality in children requiring mechanical ventilation will be useful in planning a tertiary level PICU. There is paucity of studies regarding the clinical profile, outcome of children treated with MV in PICU from Indian subcontinent.[1,3] 
While a number of clinical trials have detailed the complications of MV, most of these were conducted in adults more than a decade ago. ${ }^{[4]}$ In children, most studies were conducted before the widespread adoption of lung protective ventilation strategies or are limited to the selective consideration of Ventilator Associated Pneumonia (VAP) ${ }^{[5]}$ and extubation failure.[6-8] According to Albuali et al,[9] children are currently ventilated with a lower tidal volume ( 8.1 vs. $10.2 \mathrm{~mL} / \mathrm{kg}$ ), a lower peak inspiratory pressure ( 27.2 vs. $31.5 \mathrm{~cm} \mathrm{H}_{2} \mathrm{O}$ ) and a higher peak expiratory pressure ( 7.1 vs. $6.1 \mathrm{~cm} \mathrm{H}_{2} \mathrm{O}$ ) than 20 years ago. The impact of these recent changes in ventilatory practice and general patient care (e.g. an increase in the number of dedicated paediatric critical care beds, ${ }^{[10]}$ the implementation of different modalities and protective strategies of ventilation,[11] patient positioning and general care) on the epidemiology and incidence of MV associated complications is less well characterised. Hence, we conducted a study at the Department of Paediatrics, Government Medical College, Kozhikode, to assess the clinical profile and outcome of children treated with invasive mechanical ventilation in PICU. Government Medical College, Kozhikode is a premier teaching institute, located in the city of Kozhikode, Kerala and is a tertiary care referral centre with a well-equipped Paediatric intensive care unit.

\section{MATERIALS AND METHODS}

A prospective, cohort study was conducted in the PICU of the Department of Paediatrics, Government Medical College, Kozhikode during the period of January 2014 to June 2015. All children between age group $>28$ days to $\leq 12$ years admitted in PICU and requiring invasive ventilation for more than 24 hours were taken up for the study. Postoperative cases requiring ventilator support as well as those ventilated from another hospital for more than 24 hours and transferred to our PICU were not included.

Socio-demographic as well as clinical details of the cases included in the study were recorded using a semi-structured proforma which contained the details like age, gender, immunisation status, weight, admitting diagnosis, presence of chronic disease and immunosuppression, reason for mechanical ventilation, duration of ventilation and PICU stay, ventilator settings, complications, outcome including mortality were recorded. To complete the outcome analysis, details of the medical records of review upto one month, after discharge from the hospital were also noted.

The standard ventilator devices of the PICU were used for ventilation and the different modes used were pressure control ventilation (PCV), volume control (VCV) and synchronised intermittent ventilatory settings were done by residents on duty. The details of procedure including endotracheal (ET) tube size, initial settings of ventilator, drugs and other supports used etc. were recorded. General care of patients on ventilator were done by the nursing staff on duty. Each event of tube obstruction, suction, displacement, accidental extubation (non-elective extubation by the patient or occurring during patient care, irrespective of the need for reintubation), elective or planned extubation, need for reintubation and details of failed extubation (Reintubation within 48 hrs. of a planned extubation; excluding accidental extubation) were also recorded in detail.

\section{Statistical Analysis}

Data was entered in excel sheet and was analysed using SPSS software. Categorical data were expressed as absolute counts and percentages and continuous data were expressed as mean (SD) or median (Range).

\section{RESULTS}

Study group included 130 children, between age group $>28$ days to $\leq 12$ yrs., who were admitted in PICU and given invasive mechanical ventilation for more than 24 hours. Of this, $54.6 \%$ were males.

Mean age was 27 months with minimum age of 1 month and maximum age of 12 years. Of 130 children $59.2 \%$ were below 1 yr. of age, 26.2\% between 1 - 5 yrs., 10\% between 5 10 yrs. and $4.5 \%$ above 10 yrs. Regarding weight of children, $44.6 \%$ were below $5 \mathrm{~kg}, 27.7 \%$ between $5-10 \mathrm{~kg}, 20.8 \%$ between $10-20 \mathrm{~kg}$ and $6.9 \%$ above $20 \mathrm{~kg}$. About $29.3 \%$ of the children were unimmunised or partially immunised. Eleven children (8.5\%) were having congenital or acquired immunosuppression.

Admitting Diagnosis: In the present study, most of the children were admitted for respiratory system diseases. The system wise data is shown in Table 1.

\begin{tabular}{|c|c|c|c|}
\hline $\begin{array}{c}\text { System: Total } \\
\text { and Percentage }\end{array}$ & Disease & Frequency & $\%$ \\
\hline \multirow[t]{5}{*}{$\begin{array}{c}\text { Respiratory } 55 \\
(42.3 \%)\end{array}$} & Bronchopneumonia & 25 & 19.2 \\
\hline & Aspiration pneumonia & 17 & 13.1 \\
\hline & Acute bronchiolitis & 6 & 4.6 \\
\hline & ARDS & 4 & 3.1 \\
\hline & $\begin{array}{l}\text { Upper airway } \\
\text { obstruction }\end{array}$ & 1 & 0.8 \\
\hline \multirow{3}{*}{ CVS: $5(3.8 \%)$} & CCHD & 3 & 2.3 \\
\hline & ACHD & 1 & 0.8 \\
\hline & Aortic stenosis & 1 & 0.8 \\
\hline \multirow[t]{9}{*}{ CNS: 37 (28.5\%) } & Meningitis & 21 & 8.5 \\
\hline & Seizure disorder & 8 & 6.2 \\
\hline & Encephalitis & 7 & 5.4 \\
\hline & Neuromuscular & 3 & 2.3 \\
\hline & Meningoencephalitis & 2 & 1.5 \\
\hline & Demyelination & 2 & 1.5 \\
\hline & Intracranial bleed & 2 & 1.5 \\
\hline & Status epilepticus & 1 & 0.8 \\
\hline & Brain abscess & 1 & 0.8 \\
\hline GIT: $8(6.2 \%)$ & Liver failure & 8 & 6.2 \\
\hline $\begin{array}{c}\text { Haematological: } 3 \\
(2.3 \%)\end{array}$ & HLH & 3 & 2.3 \\
\hline \multirow[t]{3}{*}{ Others } & Sepsis & 21 & 16.2 \\
\hline & IEM & 2 & 1.5 \\
\hline & $\begin{array}{l}\text { Cervical spine } \\
\text { dislocation }\end{array}$ & 1 & 0.8 \\
\hline
\end{tabular}

Among 130 children $50.8 \%$ had underlying chronic disease, affecting cardiovascular system in $16.2 \%$ (21), GIT in $2.3 \%$ (3), nervous system in $26(20 \%)$ and other conditions such as Acute leukaemia (ALL) in 4, Immunodeficiency in 4 and Inborn error of metabolism (IEM) in 2 cases.

Indication for Mechanical Ventilation: Respiratory failure $(62.3 \%)$ was the most common cause for mechanical ventilation followed by airway protection (28.5\%) and persistent shock (9.2\%). In most of the cases decision to give 
MV was taken electively, whereas $33 \%$ of cases were intubated and ventilated on an emergency basis.

All children were orally intubated. Most of the children were intubated with uncuffed endotracheal tubes (ETT) (79.2\%). Inotropes were used in $57.7 \%$ children. Tracheostomy was done later in $3(2.3 \%)$ children. Most commonly used ventilatory mode was SIMV-PC (58.5\%) followed by SIMV-VC (28.5\%). Mean value of PEEP (Positive End Expiratory Pressure), PIP (Peak Inspiratory Pressure), Tidal volume per $\mathrm{kg}$ were $5.31,16.9,6.41$ respectively.

Reintubation was required in $59.2 \%$ children due to tube obstruction, accidental or spontaneous extubation and failed extubation. ETT obstruction occurred in $52.3 \%$ of cases and was the important reason for reintubation. Accidental extubation occurred in $31.5 \%$.

Regarding the complications, among 130 children 63 children (48.5\%) developed a total of 116 complications related to the delivery of MV. This equated to 175 complications per 1,000 days of ventilation. Failed extubation (Reintubation within $48 \mathrm{hrs}$. of a planned extubation) occurred in 29 (22.3\%) children. VAP was developed in 22 (16.9\%) children. Eighteen children (13.8\%) had post extubation stridor occurring within 2 hours of extubation. Endobronchial intubation occurred in 16 children (12.3\%). Most episodes of endobronchial intubation were diagnosed clinically, and appropriate changes were made prior to chest $\mathrm{x}$-ray taken. Perioral tissue damage occurred in 14 children (10.8\%). Twelve children (10.2\%) developed atelectasis and five (3.2\%) developed pneumothorax during the course of ventilation. All the children with pneumothorax required chest tube insertion.

Mean (SD) duration of MV was 5.1 (5.24) days. Minimum period was one day and maximum 30 days. The overall period of ventilation was 663 days. The mean (SD) duration of PICU stay was 10.2 (8.9) days.

Mortality: Total mortality among the study group was $54.6 \%$ (71 out of 130 ). Of this, $60 \%$ children belonged to less than 1 year and $26 \%$ between 1 - 5 years' age groups. Mortality was more among females (52 compared to 29 males) and in children with weight less than $5 \mathrm{~kg}$ (48\%) compared to other weight categories (20\%- between 5 - 10 $\mathrm{kg}, 21 \%$ - between $10-20 \mathrm{~kg}$ and $11 \%$ in above $20 \mathrm{~kg}$ ).

Pneumonia with sepsis was the admitting diagnosis in majority of children (54.8\%) who expired. Also, there was some underlying chronic disease in 42 out of 71 (59.1\%) children (Congenital heart disease: 16, Cerebral palsy: 11, Acute leukaemia: 4).

Mortality was $52.6 \%$ for children with MV duration $\leq 10$ days and $83.3 \%$ for MV duration $>10$ days and this was significant $(\mathrm{p}<0.05)$. In children who received $\mathrm{FiO} 2>60 \%$ for a period of $>6$ days, mortality was significantly higher compared to those who received $\mathrm{FiO} 2>60 \%$ for $\leq 3$ days $(100 \%$ vs. $48.1 \%$ with $\mathrm{p}$-value $<0.05)$. These observations suggest that the duration of mechanical ventilation and prolonged requirement of higher FiO2 are associated with mortality. Duration of PICU stay showed no significant difference.

Mortality among children who developed various complications related to MV was analysed. Failed extubation was associated with high mortality (21 out of $29-72.4 \%$ ). The mortality among other complications were $40.9 \%$ for
Ventilator Associated Pneumonia, 40.9\% for pneumothorax, $60 \%$ for atelectasis and $33.3 \%$ for post extubation stridor.

\section{DISCUSSION}

Mechanical ventilation is a frequently applied therapy in critically ill children and in many cases can be lifesaving. In the present study conducted to assess the clinical profile and outcome of children treated with invasive mechanical ventilation, most of the children were male (54.6\%) and male-to-female ratio was 1.2: 1 . Also, majority of children were below 1 yr. of age (59.2\%) and had weight below $5 \mathrm{~kg}$ (48\%). Studies done by Tanil Kendril et al,[12] Beenish Mukhtar[13] and Snezana Rsovac et al[14] also found high incidence in male children.

SIMV pressure control with pressure support (58.5\%) was most commonly used in the present study as an initial mode of ventilator support followed by SIMV volume control with pressure support $(28.5 \%)$. SIMV mode was the most commonly used initial ventilator setting in many reported studies.[12,13,15]

Most common indication for ventilation in our study was respiratory failure, which accounted for $82.4 \%$ of cases. Respiratory failure was the most common indication for MV in many studies.[14,15,16] Farias et al[17] in the study published in 2004 observed acute respiratory failure as the cause for initiation of invasive ventilation in $72 \%$ of the cases, whereas it was $64.8 \%$ in the study by Tanil Kendril et al[12] and $59.18 \%$ in a study from Brazil.[18]

Acute pulmonary disease has been reported as the main reason for the initiation of $\mathrm{MV}$ in developing countries, whereas postoperative state seems to be the main indication for ventilatory support in developed countries.[19] In the present study, most of the children were admitted for Respiratory system diseases (42.3\%) followed by CNS related diseases (29.2\%). Bronchopneumonia $(19.2 \%, \mathrm{n}=25)$ was the most common admitting diagnosis which required invasive ventilation. We have excluded post-operative cases requiring MV in our study. In studies by Tania Principi et al[16] and Tanil Kendril et al,[12] most of the children given mechanical ventilation were admitted for respiratory diseases.

The duration of mechanical ventilation was $4-6$ days in different studies.[20,21] Mean duration of mechanical ventilation in our study was $5.1 \pm 5.24$ days. Mean duration of mechanical ventilation in Snezana Rsovac et al[14] and Tania Principi et al[12] were 8.9 and 3.1 days, respectively.

\section{Complications}

Complications are common among children given invasive mechanical ventilation in PICU. Tanil Kendril et al[12] and Tania Principi et al[16] reported high rate of complications in mechanically ventilated children and was $42.8 \%$ and $40 \%$ respectively. In the present study, $48.5 \%$ children $(n=63)$ developed various complications related to MV. Rate of complications are comparable with other studies.

In the present study, MV was given for a total of 663 days. During this period a total of 116 episodes of different complications, related to invasive ventilation were noted. This equated to 175 complications per 1,000 days of ventilation. In 2011, Tania Principi et al[16] observed 114 complications per 1,000 days of ventilation.

Most common complication was failed extubation $(22.3 \%)$ and was followed by VAP (16.9\%) and post 
extubation stridor (13.8\%). Atelectasis (16.7\%) was the most common complication in the study by Tania Principi et al[16] followed by post extubation stridor (13.3\%). Tanil Kendril et al[12] reported that most common complication was atelectasis $(26.3 \%)$ followed by VAP $(17.5 \%)$. The frequency of atelectasis in the present study was $9.2 \%$. A low atelectasis rate was reported $(3.0-7.8 \%)$ in different studies.[1,3] The low incidence of atelectasis in the present study was due to the lung protective ventilation strategies with low PIP and $\mathrm{TV},[9,22]$ that we adopted in our children. Incidence of failed extubation in the present study was $22.3 \%$. In previous paediatric studies,[20] the reported incidence of failed extubation has ranged from $4.9 \%$ and $29 \%$. Differences in study population, extubation policy and definition of failed extubation applied between studies may in part account for the considerable variation in reported rate.

The major reason for reintubation in our study was impaired respiratory effort. Failed extubation was significantly associated ( $\mathrm{p}$ value $<0.05$ ) with post extubation stridor, prolonged duration of $\mathrm{MV}$, reintubation, prolonged duration of $\mathrm{FiO} 2>60 \%$ and VAP. Failed extubation was also significantly associated ( $\mathrm{p}$ value $<0.05$ ) with mortality among children given MV.

VAP is one of the important complications associated with MV. In the report by Srinivasan et al[23] frequency of VAP was $32 \%$, whereas the frequency of VAP in the present study was 16.9\%. Wang et al,[24] Tanil Kendril et al[12] and Tullu et al[25] reported a VAP frequency of $13.8 \%, 17.5 \%$ and $27.4 \%$ respectively. In our study, the occurrence of VAP was significantly associated ( $\mathrm{p}$ value $<0.05$ ) with reintubation, prolonged requirement of $\mathrm{FiO} 2>60 \%$ and prolonged duration of mechanical ventilation. The mortality related to VAP in the present study was $40.9 \%$. Tullu et al[25] reported that the mortality rate was $47 \%$ in VAP-developed patients.

Post extubation stridor was significantly associated with ( $p$ value $<0.05$ ) prolonged duration MV in our study.

\section{Mortality}

The mortality rates of children with MV were different in different studies. ${ }^{[12,13,21,26]}$ In the present study, mortality was $54.6 \%$. Tanil Kendril et al[12] reported a mortality rate of $58.3 \%$ and Traiber $\mathrm{C}$ et al[26] of $48 \%$ among mechanically ventilated children, which are close to our result. Majority of cases in the present study presented late in the advanced state of disease. In the studies by Beenish Mukhtar et al[13] and Snezana Rsovac et al,[14] mortalities were $30.3 \%$ and $38 \%$ respectively. The most likely explanation for lower rate is that in the study by Beenish Mukhtar et al from Pakistan, acute neurological illnesses (35.8\%) was the most common indication of MV and also adoption of non-invasive ventilation in the early phases of acute respiratory illness as initial mode of respiratory support, both contributing to low mortality.

In developed countries, the mortality rates of mechanically ventilated patients in PICUs were very low.[27] Mortality rate as low as $4.5 \%$ was observed by Tan et al.[28] There are several factors for this major difference in the mortality rate of MV children including higher number of postoperative cases in their PICUs, trained staff, availability of respiratory therapist for ventilatory management and early presentation of illness. Pneumonia with sepsis was the admitting diagnosis in $54.8 \%$ of our children who expired.
Also, there was some underlying chronic disease in 59.1\% of mortality cases with underlying congenital heart disease in majority. Volakli et al[29] observed that $41.3 \%$ of their cases had comorbidity in their study. Congenital heart disease was the major comorbidity observed by Payen $\mathrm{V}$ et al,[30] which is similar to the present study.

Failed extubation, prolonged requirement of $\mathrm{FiO} 2>60 \%$ and prolonged duration of MV are significantly associated with high mortality ( $p$ value $<0.05$ ) in the present study.

\section{CONCLUSION}

Most common indications for mechanical ventilation in our children was respiratory failure $(62.3 \%)$ followed by airway protection (28.5\%). Failed extubation (22.3\%) and VAP $(16.9 \%)$ were the most common complications that occurred related to invasive ventilation. The mortality (54.6\%) and complications $(48.5 \%)$ of present study are comparable with other studies. Prolonged duration of ventilation was significantly associated with complications as well as mortality related to mechanical ventilation. High rate mortality occurred in children with underlying chronic diseases.

Mechanical ventilation has become one of the major indications for admission to paediatric ICUs and often a lifesaving strategy. However, use of mechanical ventilation can be associated with various complications including patient mortality. Its use necessitates intensive monitoring as well as additional supportive care adding to the treatment cost. Most PICUs are equipped with limited number of ventilators compared to the number of sick children they cater. In this circumstance, selection of appropriate patient for ventilator support is crucial, especially in a limited resource setup.

\section{REFERENCES}

[1] Benjamin PK, Thompson JE, O'Rourke PP. Complications of mechanical ventilation in a children's hospital multidisciplinary intensive care unit. Respir Care 1990;35(9):873-8.

[2] Mutlu GM, Factor P. Complications of mechanical ventilation. Respir Care Clin N Am 2000;6(2):213-52.

[3] Rivera R, Tibballs J. Complications of endotracheal intubation and mechanical ventilation in infants and children. Crit Care Med 1992;20(2):193-9.

[4] Zwillich CW, Pierson DJ, Creagh CE, et al. Complications of assisted ventilation. A prospective study of 354 consecutive episodes. Am J Med 1974;57(2):161-70.

[5] Elward AM, Warren DK, Fraser VJ. Ventilatorassociated pneumonia in pediatric intensive care unit patients: risk factors and outcomes. Pediatrics 2002;109(5):758-64.

[6] Edmunds S, Weiss I, Harrison R. Extubation failure in a large pediatric ICU population. Chest 2001;119(3):897-900.

[7] Fontela PS, Piva JP, Garcia PC, et al. Risk factors for extubation failure in mechanically ventilated pediatric patients. Pediatr Crit Care Med 2005;6(2):166-70.

[8] Kurachek SC, Newth CJ, Quasney MW, et al. Extubation failure in pediatric intensive care: a multiple-center study of risk factors and outcomes. Crit Care Med 2003;31(11):2657-64. 
[9] Albuali WH, Singh RN, Fraser DD, et al. Have changes in ventilation practice improved outcome in children with acute lung injury? Pediatr Crit Care Med 2007;8(4):324-30.

[10] Randolph AG, Gonzales CA, Cortellini L, et al. Growth of pediatric intensive care units in the United States from 1995 to 2001. J Pediatr 2004;144(6):792-8.

[11] Marraro GA. Innovative practices of ventilatory support with pediatric patients. Pediatr Crit Care Med 2003;4(1):8-20.

[12] Kendirli T, Kavaz A, Yalaki Z, et al. Mechanical ventilation in children. Turk J Pediatr 2006;48(4):3237.

[13] Mukhtar B, Siddiqui NR, Haque A. Clinical characteristics and immediate-outcome of children mechanically ventilated in a Pediatric Intensive Care Units of Pakistan. Pak J Med Sci 2014;30(5):927-30.

[14] Rsovac S, Milosevic K, Nestorovic B, et al. Complications of mechanical ventilation in pediatric patients in Serbia. Adv Clin Exp Med 2014;23(1):5761.

[15] Harel Y, Niranjan V, Evans BJ. The current practice patterns of mechanical ventilation for respiratory failure in pediatric patients. Heart Lung 1998;27(4):238-44.

[16] Principi T, Fraser DD, Morrison GC, et al. Complications of mechanical ventilation in the pediatric population. Pediatr Pulmonol 2011;46(5):452-7.

[17] Farias JA, Frutos F, Esteban A, et al. What is the daily practice of mechanical ventilation in pediatric intensive care units? A multicenter study. Intensive Care Med 2004;30(5):918-25.

[18] Silva DCB, Shibata ARO, Farias JA, et al. How is mechanical ventilation employed in a pediatric intensive care unit in Brazil? Clinics (Sao Paulo) 2009;64(12):1161-6.

[19] Shaukat FS, Jaffari SA, Malik A. Mechanical ventilation in children - a challenge. Proceedings SZPGMI 2000;14(1):44-52.
[20] Farias JA, Monteverde E. We need to predict extubation failure. J Pediatr (Rio J) 2006;82(5):322-4.

[21] Wolfler A, Calderoni E, Ottonello G, et al. Daily practice of mechanical ventilation in Italian pediatric intensive care units: a prospective survey. Pediatr Crit Care Med 2011;12(2):141-6.

[22] Acute Respiratory Distress Syndrome Network, Brower RG, Matthay MA, et al. Ventilation with lower tidal volumes as compared with traditional tidal volumes for acute lung injury and the acute respiratory distress syndrome. $\mathrm{N}$ Engl J Med 2000;342(18):1301-8.

[23] Srinivasan R, Asselin J, Gildengorin G, et al. A prospective study of ventilator-associated pneumonia in children. Pediatrics 2009;123(4):1108-15.

[24] Wang GC, Kao HA, Hwang FY, et al. Complications in the use of mechanical ventilator in newborns: one year's experiences. Zhongua Min Guo Xiao Er Ke Yi Xue Hui Za Zhi 1991;32(4):227-32.

[25] Tullu MS, Deshmukh CT, Baveja SM. Bacterial nosocomial pneumonia in paediatric intensive care unit. J Postgrad Med 2000;46(1):18-22.

[26] Traiber C, Piva JP, Fritsher CC, et al. Profile and consequences of children requiring prolonged mechanical ventilation in three Brazilian pediatric intensive care units. Pediatr Crit Care Med 2009;10(3):375-80.

[27] Randolph AG, Meert KL, O'Neil ME, et al. The feasibility of conducting clinical trials in infant sand children with acute respiratory failure. Am J Respir Crit Care Med 2003;167(10):1334-40.

[28] Tan GH, Tan TH, Goh DYT, et al. Risk factors for predicting mortality in a paediatric intensive care unit. Ann Acad Med Singapore 1998;27(6):813-8.

[29] Volakli E, Sdougka M, Tamiolaki M, et al. Demographic profile and outcome analysis of pediatric intensive care patients. Hippokratia 2011;15(4):316-22.

[30] Payen V, Jouvet P, Lacroix J, et al. Risk factors associated with increased length of mechanical ventilation in children. Pediatr Crit Care Med 2012;3(2):152-7. 